\title{
Relationship between Population and Woody Plants Distributions in Pella District, Hong Local Government Area, Adamawa State, Nigeria
}

\author{
E. N. Gandapa* \\ Department of Geography, Nigerian Defence Academy, Kaduna, P.M.B 2109, Kaduna, Kaduna State, Nigeria \\ *Corresponding Author: E. N. Gandapa, Department of Geography, Nigerian Defence Academy, \\ Kaduna, P.M.B 2109, Kaduna, Kaduna State, Nigeria
}

\begin{abstract}
In rural areas there is difference in tree distributions around high, moderate and low populated settlements. The study assesses the relationship between population and tree distribution on the affected areas of Pella District in 2018. Data on population figure was obtained from National Population Commission while tree numbers were generated from the field using sample quadrats. The data were used to determine the relationship between population and tree distributions near high, moderate and low populated settlements. The result of correlation analysis reveals negative, but high correlation $(r=-0.80)$ while $64 \%$ form the percentage of determination between population and tree distributions. The distribution of tree stands varies from 10, 13 and 37 on $900 \mathrm{~m}^{2}$ near high, moderate and low populated settlements respectively. Arable farming is the major causes of tree removal due to continuous annual clearing and clean weeding. The result implies with increase in population there is decrease in tree distributions and vice versa. The over dependence by man on soil fertility and vegetation has impacted tree distribution harmfully. The result recommends adoption of mixed cropping, crop rotation and orchard gardens that are environmental friendly to conserve tree distributions.
\end{abstract}

Keywords: 1. Human population 2.Tree distribution 3. Human activities 4. Relationship 5.Sample quadrates 6. Sample settlements

\section{INTRODUCTION}

There exists relationship between population and environment. As human population grows the consumption of natural resources increases (Kate, 2016). This is because more people use more fertile soil to produce food, more land to construct shelter and roads that causes massive woody plants removal (Tilman and Lehman, 2017). Amongst all the environmental resources, vegetation cover is the most observable resource that is affected adversely by changes in land use manifested by increase in population (Choudhary, 2019).

In developing country like Nigeria, local environmental problems such as reduction in woody plants cover arise from inappropriate agricultural practices, population concentration, prolonged over harvesting, and inadequate environmental management (National Academy of Science, 2018). The constant rise in human population during the twentieth century in developing countries is the fundamental cause of loss of natural vegetation due to continuous exploration of arable land for food production, increase in fuelwood harvesting, and expansion of road and shelter Academy Room, 2013). In Pella District, the populace significantly depends on fuelwood to generate domestic energy, and massively clear woodlands to cultivate crops. The over exploitation of woodlands and soil fertility have caused reduction in woody plants crowdedness.

\subsection{Statement of the Research Problem}

Result of study observed that the relationship between population increase and vegetation removal in most of the developing countries has deepened the concern on devegetation (Nath and Mchahary, 2012). This is because the rural populace depends significantly on environmental resources such as soil fertility for crop production, and vegetation for shelter materials and fuelwood, and massively clear vegetal cover for road and shelter constructions (Gandapa, 2014). 
From the literatures, woody plants are degrading due to increase in dissimilar human activities manifested by increase in population, but there is not at all assessment between indigenous woody plants distribution and population. It is this limitation that this research was embarked upon to solve at a micro-scale study by assessing the relationship between population and woody plants distribution in Pella District of Hong Local Government Area, Adamawa State.

In Pella District population has increased by 10.05\% from 1991 to 2017 (National Population Commission, 2017). Thus, density increased from 38 to 70 persons per $\mathrm{km}^{2}$ while land per person decreased from 2.6 to $1.4 \mathrm{~m}^{2}$. Hence, the crowdedness of woodlands is decreasing due to expansion of farmlands, and increase in fuelwood consumption. There is probability that if the unwise exploitation of soil fertility and woodlands persists there will be extinction of indigenous woodlands around settlements in Pella District. Result of field observations in Pella District revealed there exist differences in indigenous woodland distributions around high, moderate and low populated settlements. The study was conceived from the hypothesis that there is no statistically significant relationship between the activities of increasing population and decrease in woody plants distributions around settlements.

\section{AIM AND OBJECTIVES OF THE STUDY}

The aim of the study is to identify the relationship between woodlands and population distributions in Pella District. The objectives include: to identify settlements and corresponding population of the district in 1991 and 2017; to highlight human activities that affects woody plant cover unfavorably; and to determine tree numbers near high, moderate and low populated settlements. The scope is restricted to Pella District. The concern is to determine the relationship between population and tree distribution in 2018.Thepopulation of the study is number of people and trees. The study is restricted to indigenous woody plants because of the concern for the increasing reduction in crowdedness, but excludes exotic species because they are managed.

\subsection{Justification of the Study}

The study was embarked upon due to the observed difference in distribution of indigenous woodlands around different categories of settlements. The study has categorized the settlements into high, moderate and low based on human number, and have estimated woodland distributions around the varied categories. The result of the study is significant to environmental policy makers by identifying the causes of reduction in woodlands crowdedness around settlements for policy formulation on how to manage socio-economic activities of high population and woodland distributions. Also the findings will raise the awareness of the individual and community to adapt wise harvesting of woodlands, and preserve seedlings and saplings during annual clearance and clean weeding for woody plants regeneration.

\subsection{Review of Related Literature}

From the point of system theory there is relationship between man and environment. Because systems harmonize environment, man and animal to interacts together in a single framework (Academic Room, 2013; la Cour, 2006). Likewise, environmental systems sustains the interaction between the diverse abiotic and biotic components of the lithosphere_Pidwirny, 2006). However, a change in the attributes of the environmental systems affects the function unfavorably. For example, exploitation of soil fertility leads to degradation of vegetation cover. From the concept of "Tragedy of the Commons" human beings are unable to manage the environmental resources such as soil fertility and vegetation cover when poor and populated (Hardin, 2010). This is because the poor man exploits any accessible resources without sustainability.

Result of study reveals the vegetation that influences quality of life of the rural communities by providing fuelwood the major source for generating domestic energy, native fruits and vegetables, herbs and shelter materials have reduced in distribution. Therefore, understanding the relationship between tree distributions and human activities in rural areas are fundamental for environmental rural resource studies (Pozziand Small, 2002).

Result of studies between population growth and vegetation removal in Central America, East and West Africa, and South Asia reveal a strong relationship because people clear vegetation massively to 
cultivate crops, and selectively to harvest wood products (Meyerson, 2004). Nath and Mwchahary (2012) found that vegetation removal was significantly related to the rate of population growth in most countries in Africa from 1968 to 1978, and increase in population is recognized as a primary driver for considerable devegetation in developing world. Similarly, population growth was responsible for 79\% of global vegetation removal between 1973 and 1988 (Nath and Mwchahary, 2012). Pozzi and Small (2002) stated that quantitative description of tree abundance in rural areas provides a basis for comparison of the vegetal environment in which most Nigerians resides.

Results of studies especially those of Meyerson (2004); Nath and Mwchahery (2012); and Pozzi and Small (2002) are important by stating that there exist relationship between population and vegetation cover. However, the studies did not quantify the relationship between human and woodland distributions neither restricted the studies to Adamawa State nor carried out a micro scale study on assessment of the relationship between population and indigenous woodlands in Pella District of Hong Local Government Area.

The literature review focused on identifying the types of vegetal resources that are harvested and human activities that reduce woody plants distribution around settlements. The literatures revealed that woody plants are affected adversely by arable farming, pastoralism, fuelwood harvesting, settlement and road constructions manifested by increase in population.

\subsection{Geographical Background of the Study Area}

Pella District is approximately located between latitude $09^{0} 59^{\prime} \mathrm{N}$ to $10^{\circ} 01$ ' $\mathrm{N}$ and between longitude $12^{0} 45^{\prime} \mathrm{E}$ to $13^{0} 00^{\prime} \mathrm{E}$ (Garkida, Nigeria, Sheet 155 ). The district is located in Hong Local Government Area of Adamawa State, Nigeria. It has an approximate landmass of about $450 \mathrm{~km}^{2}$.

The rainy season usually starts in May and end in October with highest amount of rainfall in August and September. The mean annual rainfall ranges from 700 to $1000 \mathrm{~mm}$ while the mean daily temperature is between $36^{\circ} \mathrm{C}$ to $41^{\circ} \mathrm{C}$ of the dry season to about $20^{\circ} \mathrm{C}$ to $25^{\circ} \mathrm{C}$ during the wet season (Online Nigeria, 2017).

The soils are derived from the weathered basement complex and old sedimentary rocks (Gandapa, 2014). The soils are deep, well drained and has lateritic crust in most areas. Fluvial soils occur on the floodplains of rivers Fa'a, Ngilang and Bubulum that are associated with dense woody plant cover, but have been affected significantly by cultivation on crops like rice, sugar cane, maize and guinea corn. The relief and landforms are generally hilly with highlands ranging from about 426 to $1158 \mathrm{~m}$ above mean sea level (Garkida, Nigeria, Sheet 155). The hilly landscape favour sparse vegetation cover due to poor water holding capacity, high surface run-off, and hard rock outcrop that restricts the development of crowded woody plant cover (Gandapa, 2014).

The Pella District falls within the Sudan vegetation zone characterized by sparse woody plants distributions that are short (Adoti, 2018; Makinwa, 2018). Tree species like Acacia albida and Anogeissusleiocarpus shed leaves and remain dormant during most of the dry (Gandapa, 2014).

Materials such as fuelwood, shelter materials, fibre, pulp, wild fruits and vegetables are harvested from the vegetation, but access to these materials have been reduced due to massive vegetation removal for arable farming and selective harvesting. Most trees within the populated settlements are exotic species such as Azadirachtaindica, Eucalyptus camaldulensis, Psidiumguayava, Mangiferaindica and Phoenix sylvestric. The population increased from 17,162 in 1991 to 31,470 in 2017 (National Population Commission, 2017). About 90\% of the populace depends on arable farming on crops like Arachishypogaea, Sorghum vulgare,Zea mays and Phaseoluscoccineus among others. Most of the household use wood as a basic fuel to generate domestic energy (Gandapa, 2014).

\section{Materials ANd Methods}

Data required for the study include human and woodland numbers. Others include environmental resources harvested like vegetation, fuelwood and soil fertility. Human population and tree numbers were used to determine the relationship while those on resources harvested were used to highlight the implications on vegetation removal. Data on tree numbers were generated from the field using sample quadrats while those on resources harvested were generated from the respondents using interview 
schedule. Human population for 1991 and 2017 were generated from 2006 Population and Housing Census (National Population Commission, 2017).

To ensure coverage of the study area $\left(450 \mathrm{~km}^{2}\right)$ within a limited time, the settlements were categorized into 3 groups based on population size: high (2090 to5364); moderate (1122 to1260); and low (159 to 203). From each category, 3 sample settlements with the highest population in 2017 were selected. This is to fair distributions and estimation. For settlements with the highest populations Pella (5364), Uding (2962) and Zhedinyi (2090) were selected. To determine sample settlements with moderate population, average population of all the settlements indicate 1124. Therefore, the first 3 settlements whose populations vary insignificantly from the mean (1124) were selected. Using this criterion, Ngalbi (1257), Shibi (1122) and WuroBokki (1260) were selected. More importantly, settlements with the lowest population such as Tubha (159), Dol Bali (178) and DolFafa (203) were included.

To determine tree distributions, 4sample quadrats measuring $15 \mathrm{~m}$ by $15 \mathrm{~m}$ were established based on the 4 cardinal points. The size $\left(225 \mathrm{~m}^{2}\right)$ is considered suitable to generate woodland distribution on farmlands near settlements. The quadrats were purposively located to avoid areas devoid of tree stands like access roads, school compounds; to evade establishment within settlements; and to ensure they are within 1 to $2 \mathrm{~km}$ from the edges of the sample settlements. Figure I show the 9 sample settlements and 36 quadrat samples.

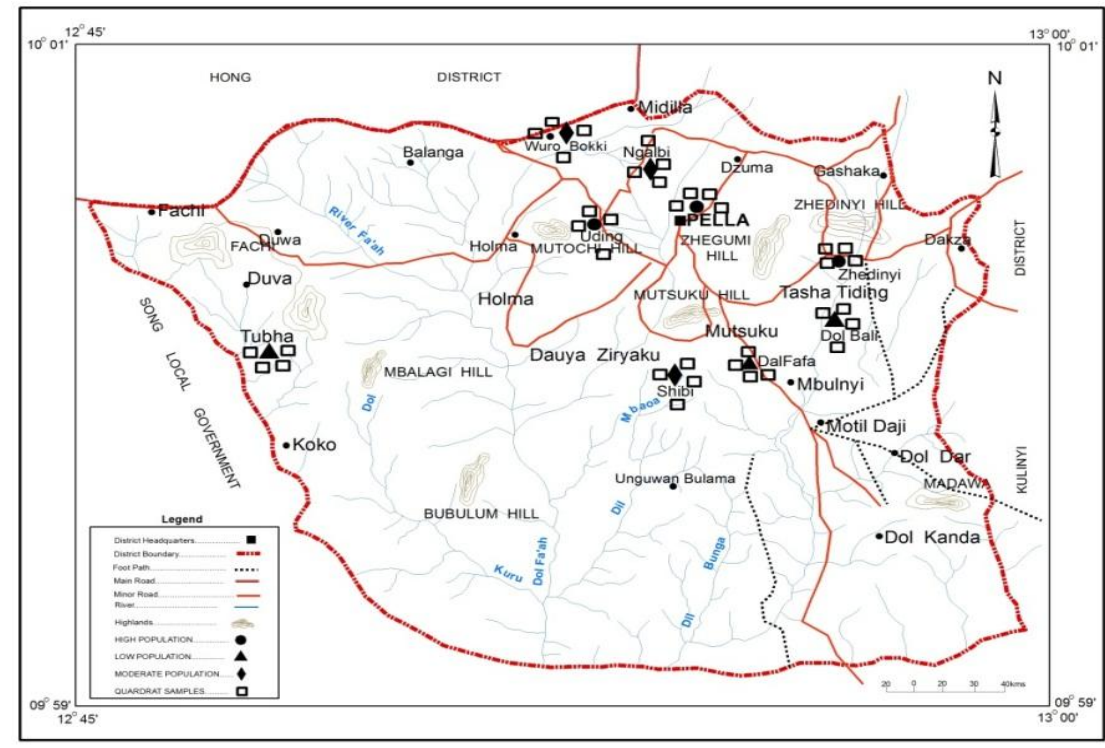

FigureI: Sample Settlements and Quadrats

The area covered by each of the 3 categories of settlements is $2700 \mathrm{~m}^{2}$ while the total area covered by the 36 sample quadrats is $8100 \mathrm{~m}^{2}$. The objective was to determine tree number within the 3categories of sample settlements.

Approaches adapted to pair human population of the 9 sample settlements to tree numbers on $2700 \mathrm{~m}^{2}$ around each category of settlement include: First, the populations of all the sample settlements classified as high, moderate and low were summed up separately to generate 3 sets of independent variables. Secondly, the number of tree stands observed on each of the 4sample quadrats established round high, moderate and low populated settlements were summed up to produce 3 sets of dependent variables. Thirdly, to pair the observed tree numbers to the sample population, sum of the populations of high, moderate and low settlements were separately paired to the sum of tree numbers observed around each set of the settlements. They are paired to identify the relationship between population and tree numbers within the local environment using Pearson's product-moment correlation coefficient.

Interview schedule forms were used to generate data from the respondents on environmental resources harvested. Selective and availability sampling techniques were used to choose the households and respondents. The sample frame consists of both adult male and female. The respondents are people assumed to perform certain activities that are related to vegetation removal. Sample size of 430 respondents was interviewed. The distribution was proportionally according to the population ofthe 9 sample settlements. 
To project the population of Pella District from 17,162 in 1991 to 31,470 in 2017, arithmetic method was accepted than geometric because it gives more conservative results (Zohry, 2012). The population growth rate of 2.6\% was used to project the population (World Data Atlas, 2016).Data on human population and tree numbers were analyzed using Pearson's product-moment correlation coefficient while " $t$ " test at $0.05 \%$ confidence limit was used to determine the statistical significance of the difference between the two sample means [human population and tree stands] (Leilei, Jianrong and Yang, 2014; Herrmann, Anyamba and Tucker, 2011.

\section{RESUltS AND DisCUSSIONS}

The population increased from17, $162(12.18 \%)$ in 1991 to $31,470(22.33 \%)$ in 2017 , the density increased from 43 to 70 persons per $\mathrm{km}^{2}$ while the per capita decreased from 2.3 to $1.4 \mathrm{~m}^{2}$.The population of the sample settlements indicates 14,595 while 60tree stands were observed on the total sample plots of $8100 \mathrm{~m}^{2}$.The tree numbers per $900 \mathrm{~m}^{2}$ varies from 10,13 and 37 around high, moderate and low populated settlements accordingly. The productive purposes to which land cover are engaged include arable farming, settlement, reserve and road network. The predominant cause of massive woody plants removal is arable farming and constructions while fuelwood harvesting causes species removal.

\subsection{Trends in Human Populations and Tree Distributions}

The results on population of sample settlements and observed tree stands are presented on Table 1 . The human population varied from 10416, 3639 and 540 for high, moderate and low populated settlements accordingly. These correspond to 10,13 and 37 tree stands per $2700 \mathrm{~m}^{2}$ each.From the results, with increase in activities of high population like arable farming and fuel wood harvesting lead to decrease in tree stands in Pella District.

Table1: Distribution of Sample Settlements, Human Populations and Tree Stands

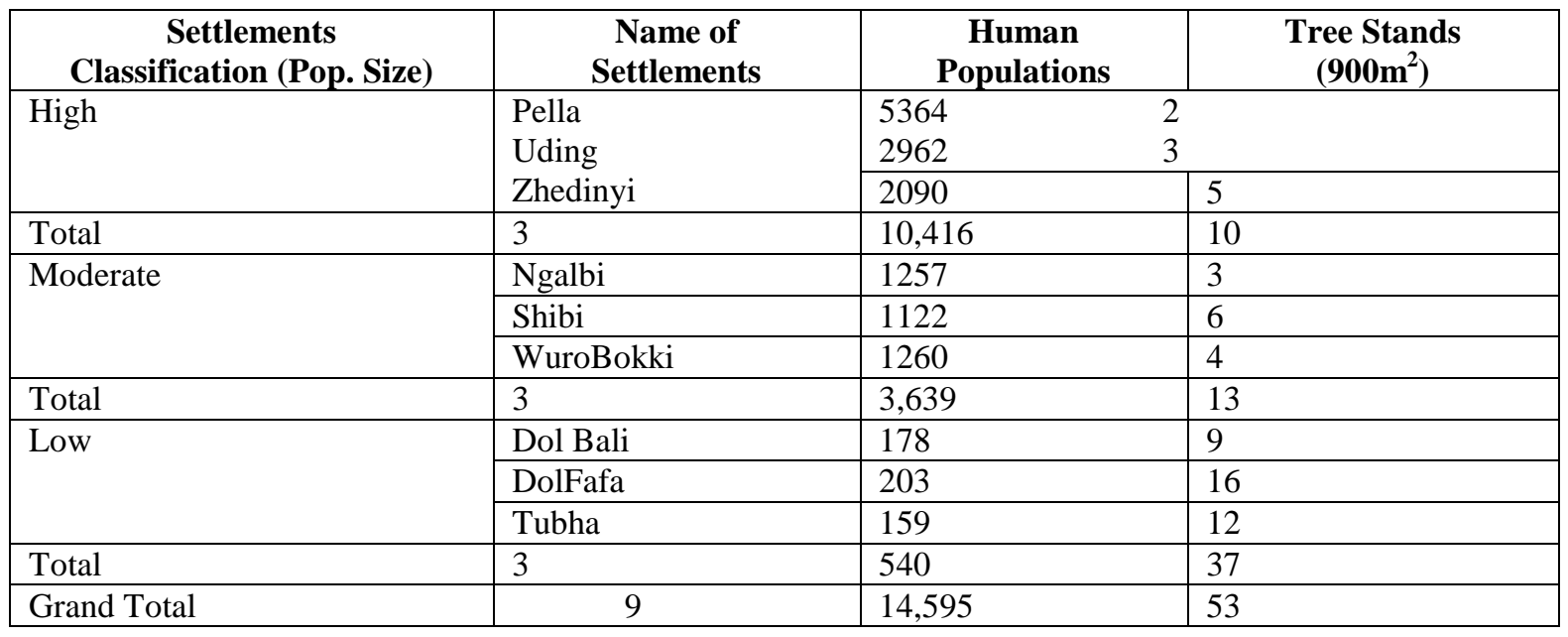

Source: Field Study, 2018

\subsection{Major Causes of Tree Removal}

Table 2 presents summary of the respondents' views on the major causes of tree removal in Pella District of Hong Local Government Area, Adamawa State.

Table2: Respondents' Views on Major Causes of Tree Removal

\begin{tabular}{|l|l|l|l|}
\hline S. No. & \multicolumn{1}{|c|}{ Causes } & \multicolumn{1}{c|}{ Respondents } & \multicolumn{1}{c|}{ Percentage } \\
\hline 1. & Arable farming & 213 & 49.53 \\
\hline 2. & Fuelwood harvesting & 101 & 23.49 \\
\hline 3 & Infrastructural development & 61 & 14.19 \\
\hline 4. & Pastoralism & 40 & 9.30 \\
\hline 5. & Others & 15 & 3.49 \\
\hline & Total & 430 & 100.00 \\
\hline
\end{tabular}

Source: Field Study, 2018 
From Table 2, $49.53 \%$ of the respondents stated that arable farming is the leading economic activity that affects tree distribution adversely. This is because majority of the populace practice varied systems of crop cultivation like rotational bush fallow, mono cropping, crop rotation, mixed cropping and continuous cropping. These systems of farming place a piece of farmland on annual clearing and cultivation. The farmers adopt slash-and-burn as a means of farmland clearing, plow the soil using tractor and ox-drawn plows, and clean weeding using herbicide or hoe. These systems of crop management do not allow regeneration of woodlands on farmlands due to annual routine.

According to the respondents, the long history of existence of settlements with high population and longer period (about 50years) of arable farming is responsible for the occurrence of least (10) tree stands around Pella, Uding and Zhedinyi. This explains why most of the farmlands on continuous cultivation have few preserved tree species such as Vitellariaparadoxa, Tamarindusindica and Parkiabiglobosa. Such species are preserved because they have broad crown that serve as wind break, provide shade, and have edible fruits.

From $23.49 \%$ of the respondents, fuelwood harvesting is the major cause of tree removal near settlements. This is because most of the households depend on fuelwood for generation of domestic energy. For this reason, around Pella, Uding and Zhedinyi that have population within 2090 to 5364 there are 10tree stands on plot of $2700 \mathrm{~m}^{2}$ as shown on Table 1 . The reason for the occurrence of 10trees is attributed to excessive and prolonged harvesting of the preserved tree branches for fuelwood, and scraping of the bark for medicinal purposes that seldom lead to drying up. Likewise, around Ngalbi, Shibi and WuroBokki that are moderately populated there are 13 stands per $2700 \mathrm{~m}^{2}$ as shown on Table 1. These settlements with population ranging from 1122 to 1257 are characterized by low demand for fuelwood because the population is moderate and the energy demand for domestic purpose like cooking is comparative to the population. More importantly, some households infrequently use alternative biofuel like crop residues (maize cup and cornstalk) to generate domestic energy with positive advantage on tree conservation.

Around settlements with populations varying from 159 to 203 like Tubha, Dol Bali and DolFafa there are 37 tree stands on $2700 \mathrm{~m}^{2}$ as shown on Table 1 . The reasons for the occurrence of highest (37) tree stands are attributed to the low population of the settlements. Also the settlements are at the fringes of reserve lands from where residents could harvest dry tree stands for energy generation with broader advantage on conserving trees around the settlements. More importantly, the population is low (159 to 203); therefore, the households require small quantity of fuelwood to generate energy for cooking.

Table 2 indicate $14.19 \%$ of the respondents are of the opinion that infrastructural development such as road networks and shelters are the major causes of depletion in tree stands around settlements. For example, there is massive removal of trees on sites to construct houses and roads. Within high populated settlements (Pella, Uding and Zhedinyi) that are characterized by more infrastructures like houses, access roads, clinics and schools there are 10 tree stands on $2700 \mathrm{~m}^{2}$ compared to 13 and 37 around moderate and low populated settlements as shown on Table 1.

From Table 2, 9.30\% of the respondents identified that pastoralism is an important factor responsible for reduction in tree stands near settlements. This is because livestock such as bulls, sheep and goats are managed on natural pastures like grasses, leaves, and periodically on crop residues. With increase in household sizes that are predominantly arable farmers has caused increase in number of bulls to serve as source of farm labour.

Within more populated settlements like Pella, Uding and Zhedinyi there are more than three herds (300 bulls) that are combined under the care of a hired community herdsmen. During the dry season (March to May) characterized by inadequate pastures branches of tree species like Kaya grandfoliale and Acacia albida are lopped to feed the bulls on palatable foliage and pulp. The lopping is more intense near populated settlements due to more herds than moderate and low settlements with fewer bulls. The persistent lopping of the few preserved trees further hastens reduction in distribution because the stands sometimes dry up.

Around moderate populated settlements (Ngalbi, Shibi and WuroBokki) the occurrence of 13 tree stands per $2700 \mathrm{~m}^{2}$ as shown on Table 1is associated with few bulls of about 30 per settlement while there are about 15 in low populated settlements. Due to few bulls ranging from 15 to 30 in moderate 
and low populated settlements there is insignificant lopping of tree branches at the advantage of woodland conservation. Although, the study did not consider species of trees, however, the lopping approaches adopted by the herdsmen could be the reason for the occurrence of rare species like Kaya grandfoliale around settlements that have high population of bulls.

From the result, $3.49 \%$ of the respondents indicate that other activities like harvesting of woody plants products such as haft, charcoal, flail and yoke are responsible for the reduction in tree stands around high, moderate and low populated settlements. The selective harvesting of species like Prosopisafricana for charcoal near high populated settlements like Pella, Uding and Zhedinyi is responsible for the low (10) distribution of trees on $2700 \mathrm{~m}^{2}$ as shown on Table 1.

\subsection{Correlation between Human Populations and Tree Distributions}

The result of correlation coefficient between increasing human population and tree stands reveal a negative, but high correlation $(\mathrm{r}=-0.80)$. The percentage of determination that tree distribution is dependent on human population is $64 \%$. Other factors such as drought, wind throw, plant parasites and old age of trees that could cause reduction in tree distributions apart from human activities accounted for $36 \%$ influence. When the result of the two means (human populations and tree stands) were subjected to ' $t$ ' tests the result indicated 1.34 for computed ' $t$ ' value and 6.31 for critical ' $t$ ' at $0.05 \%$ confidence limit. Comparing value of the computed ' $t$ ' to critical' $t$ ' the result falls within the accepted region. Based on the results, the null hypothesis that there is no statistical correlation between population increase and tree distribution is rejected. Hence, the alternative that there is statistical relationship between population trend and tree distribution is accepted.

The result implies with increase in human population by 14,308 from 1991 to2017 manifested by increase in diverse human activities such as arable farming, fuelwood harvesting and constructions leads to decrease in tree stands especially near populated settlements such as Pella, Uding and Zhedinyi.

It is important to state that the test did not take into consideration other factors like drought, storm, natural death and plant parasite that could cause reduction in tree distributions near settlements. Likewise, the study did not consider number of people coming from outside the sample settlements that could accelerates reduction in tree distribution through fuelwood harvesting and arable farming nor consider restricted areas.

More importantly, population per se is not in any way responsible for reduction in tree distributions, but the socio-economic activities of the people residing in Pella District. Thus, population increase merely facilitates diverse and increase in human activities like arable farming, fuelwood harvesting and settlement constructions that decrease tree stands. Any management strategy against woody plants degradation in rural communities like Pella District should target social, economic and cultural activities that have direct impact on the trees, but not high population.

To this end, there is homogeneity between the result of the study to those of Tilman and Lehman (2017); Nath and Mwchahary (2012);Meyerson (2004); and Pozziet al (2002). Thus, there is strong relationship between population growth and woody plants removal. This is because the woodlands that influence quality of life of the rural populace is reducing in distribution due to increase in human activities such as arable farming and wood harvesting.

\section{CONCLUSION}

The over dependence by man on rural resources such as soil fertility and vegetation has tended toward negative implication on tree distributions. About $90 \%$ of the population of the area is dominated by arable farmers and other related occupations that adversely reduce tree distributions. The relationship indicates with increase in population leads to decrease in tree distributions especially near settlements that are more populated. It is on the basis of the above perspectives that the research assessed the relationship between population and tree distributions became imperative.

It is the hope of the study that some empirical relationship will be established and some strategy developed to promote a harmonious partnership between man and his environment in Pella District. Such a harmonious partnership between man and environmental resources base can be seen through system analysis and better known in developmental cycle as sustainable environmental management. 


\section{RECOMMENDATIONS}

The strategies for sustained vegetation management and the reduction of devegetaion problems require careful use of the environment by farmers. Such cares can be introduced through the application of conservation techniques that can be achieved through adoption of tree planting programme. This is a control measure in the form of shelter belts and woodlots. Species of native trees that are traditionally used by the indigenes as economic trees like Vitellariaparadoxa, fast growing and drought resistant species such as Azadirachtaindica, Eucalyptus camaldulensis, Anacardiumaccidentale and Vitellariaparadoxa should be brought to cultivation and domestication to protect the soil, help in reverting the vegetal cover, and rehabilitate large tracts of degraded farmlands in the area.

Public awareness campaign should be embarked upon by agricultural extension workers. It is the duty of agriculturalists to educate peasant farmers to adopt farming techniques and systems that can help reduce the effects of cultivation on tree removal. These systems include crop rotation, rotational bush fallow where it is possible, mixed cropping and mixed farming. Selective use of agro-chemicals like herbicide should be encouraged based on research findings that prove to be environmental friendly.

The results suggest the need to adopt management strategies like family planning to reduce increase in population; encourage tree planting near settlements to replace those that are cut down; promote the use of other sources of generating domestic energy like kerosene; and encourage the adoption of environmental friendly arable farming techniques like mixed cropping.

\section{ACKNOWLEDGEMENTS}

I am grateful to Professor M.M. Daura and Professor J.K. Nyanganji for their valuable inputs on the manuscript. Others include Sunday A. Dibal, Edmond N. Gandapa and Jackson I. Matapa for their contributions during data collection.

\section{REFERENCES}

[1] Academic Room (2013).System Theory. Retrieved fromhttp://www.academicroom.com/topics/what-issystems-theory. Accessed 6th November, 2017

[2] Adoti, O. (2018). Three major types of vegetation in Nigeria. Retrieved from https://www.legit.ng/112806 5-three-major-types-vegetation-nigeria.html. Accessed $9^{\text {th }}$ March, 2019

[3] Choudhary, V.(2019). Population Growth and Its Impacts on Nature and Natural Resources.Retrieved fromhttp://natureconservation.in/population-growth-and-its-impacts-on-nature-and-natural-resources/ Accessed 20 January, 2019

[4] Garkikda, Nigeria, Sheet 155

[5] Gandapa, E.N. (2014). Analysis of Effects of Human Activities on Vegetation of Hong Local Government Area,

[6] Adamawa State, Nigeria. Geography Department, Unpublished Ph. D. Thesis. Nigerian Defence Academy, Kaduna, Nigeria. Pp. 15, 32, 98, 114, 139

[7] Hardin, G. (2010). The Tragedy of the Commons.American Association for theAdvancement of Science 162(3859)1243-1248. Retrieved from https://search.yahoo.com/ysh/search?hspart=adk\&hsimp=yhs-adksbyhp\&p=traged + of + the + commons $\&$ param $2=5 \mathrm{da} 9 \mathrm{e} 2 \mathrm{~d} 2-\mathrm{ad} 6 \mathrm{~b}-48 \mathrm{a} 4-9361-\mathrm{m} 4=$ googlesearch - goolesearch Accessed 26th October, 2017

[8] Herrmann, S.M., Anyamba, A. and Tucker, C.J. (2011). Exploring Relationship between Rainfall and

[9] Vegetation Dynamics in the Sahel Using Coarse Resolution Satellite Data. Retrieved from https://search. yahoo.com/yhs/Search=https://search.yahoo.com/yhs/search=googlesearch-googlesearch-v3- relationship +between+rainfall+and+vegetation+dynamics+in+the+sahel+using+coarse+resoltion+satellite+data Accessed 26th October, 2017

[10] Kate, M. (2016).How does Human Population Growth Affects Natural Resources? Retrieved from https://socratic.org/questions/how-does-human-population-growth-affect-natural-resourcesAccessed October 28, 2018

[11] laCour, A. (2006). The Concept of Environment in System Theory.Cybernetics \&Human Knowing 13(2)Pp. 41-55. Retrieved from 4http://www.ingentaconnect.com/content/imp/chk/2006/00000013/00000002/ art00004. Accessed 6th October, 2017

[12] Leilei, L., Jianrong, F. and Yang, C. (2014). The Relationship Analysis of Vegetation Cover, Rainfall and Land 
[13] Surface Temperature Based on Remote Sensing in Tibet, China. IOP Publishing. Retrieved from https://search.yahoo.com/yhs/search?hspart=adk\&hsimp=yhsadk_sbyhp\&p=Leilei+et+al+2014\%3a+veget ation+index\&param2=5c15f644-3773-4647-ae04- Accessed 29th November, 2017

[14] Makinwa, E. (2018). Vegetation Zones in Nigeria and their Features. Retrieved from https://www.legit.ng/ 1096264-vegetation-zones-nigeria-features.html Accessed $9^{\text {th }}$ March, 2019

[15] Meyerson, F. A. B. (2004). Population Growth and Deforestation: A Critical and Complex Relationship. Retrieved from http://www.prb.org/Publications/Articles/2004/PopulationGrowth Deforestation Acritical and Complex Relationship.aspx Accessed $2{ }^{\text {nd }}$ September, 2017

[16] Nath, D.C. and Mwchahati, .D.D. (2012). "Population Increase and Deforestation: A Study in Kokrajhar District of Assam, India” International Journal of Scientific and Research Publications. 2 (10) ISSN 2250-3153Retrieved from https://search.yahoo.com/yhs/searchp=the+relationship+between+population+ and+trees+density. Accessed 2nd September, 2017

[17] National Academy of Sciences (2018).Population Growth, Resource Consumption, and the Environment. Retrieved fromhttps://www.nap.edu/read/9148/chapter/5\#7Accessed October 28, 2018

[18] National Population Commission (2017).2006 Population and Housing Census, Nigeria. Priority Table Vol. iv. Pp. 13, 14

[19] Online Nigeria (2017).Climate of Nigeria. Retrieved from http://www.onlinenigeria.com/links/adv.asp? blurb=70 Accessed 26th January 2017

[20] Pidwirny, M. (2006). "Glossary of Terms: S". Fundamentals of Physical Geography (2nd Ed.).Retrieved from http://www.physicalgeography.net/physgeoglos/s.html.Accessed 17th September, 2017

[21] Pozzi, F. and Small, C. (2002). Vegetation and Population Density in Urban and Suburban Areas in USA Retrieved from http://r.search.yahoo.com/_ylt=A0LEVrg5fKpZGp4AIoPxQt.;_ylu=X3oDMTydDI5cXV uBGNvbG8DYmYxBHBvcwM2BHZ0aWQDBHNIYwNzcg Accessed 2nd September, 2017

[22] Tilman, D. and Lehman, C. (2017). Human-caused Environmental Changes: Impact on Plant Diversity and Evolution. Retrieved from http://www.pnas.org/content/98/10/5433.fulAccessed 2nd September, 2017

[23] World Data Atlas (2017).Nigeria - Population - Rate of natural increase (online). Available at: https:// knoema.com/atlas/Nigeria/topics/Demographics/Population/Rate-of-natural-increase.Accessed16th September, 2017

[24] Zohry, A. (2012). Methods of Measuring Population Change. Retrieved from http://r.search.yahoo.com/ ylt=A0LEVjwT3a9ZxpUAgs0PxQt.; ylu=X3oDMTBysWNmY2MwBGNvbG8DYmYxBHBvcwM0BHZ 0aWQDBHNIYwNzcgAccessed 6th September, 2017

Citation: E. N. Gandapa. "Relationship between Population and Woody Plants Distributions in Pella District, Hong Local Government Area, Adamawa State, Nigeria”. International Journal of Research in Geography. vol 6, no. 1, 2020, pp. 01-09 doi: http://dx.doi.org/10.20431/2454-8685.0601001.

Copyright: (C) 2020 Authors. This is an open-access article distributed under the terms of the Creative Commons Attribution License, which permits unrestricted use, distribution, and reproduction in any medium, provided the original author and source are credited. 